\section{FALSE STATEMENTS CONCERNING CAUSES OF ORAL PATHOLOGY.*}

\section{S. BLAIR LUCKIE, D.D.S. Cirester, Pa.}

To state a cause of a diseased condition, without the conclusion being formulated by logical reasoning, which should always accompany clinical inquiry, is misleading. When such a statement appears in a journal devoted to scientific thought it is likely to be accepted as authority, especially if the statement emanates from one supposed to have made a study of the etiology of disease within the region referred to in the opinion expressed.

Ability to recognize causes and defend the part they take in producing effects is proportional to knowledge acquired by study and observation. The process of reasoning is the distinguishing of truth from falsehood, the deducing from evidence an understanding of a proposition. To express with exactness is to comprehend in jts fulness.

A pathologic condition is an effect; a comprehension of its causes is a result of an appreciation of phenomena associated with the region affected. Pathology has its loasis in physiology and physiology its foundation in inatomy. To comprehend the anatomy of the animal machine we must take it apart, analyze it, and recognize the construction of the parts by the harmony of their association. All those agents or influences capable of deranging either directly or indirectly the structure or functions of the machine are causes of pathologic conditions, and their study as producers of such is technically known as etiology. In the pursuit of the study it is essential, in order to appreciate the influences that operate to weaken or alter structural arrangement and prevent normal function, to have in mind the construction and function of the machine in health.

To assume a cause may be necessary in the absence of sufficient knowledge to immediately express a decision, and is legitimate in pursuing the investigation into that which is obscure. The assumption then is a working hypothesis and should be supported by demonstrated facts ascociated with something analogous to that under discussion. In the realm of abstract thought a discussion may thus be conducted and an opinion formed whereby one may be guided in his action. In diagnosing and the pursuit of knowledge as to causes of disease the unknown may become more intelligently understood by such a course of reasoning.

The hearsay of the ignorant may be proven when submitted to analysis. 'To say an inflamed dental pulp is a cause of pain in the ear may be assumed, but it requires a familiarity of the distribution of the fifth pair of nerves, the indeterminate character of impulses conreved to the brain, which are so often symptomatic of pulpitis, and the finding of an inflamed pulp to warrant an opinion and institute treatment.

\section{A PRESUMPTIVE STATEMENT.}

In Tun Joursal of the American Medical Association May 19, 1906, page 1516, appears this sentence: "The practice of dentists of covering teeth with crowns of metal is one of the most frequent causes of sinus affection." This sentence is a part of an article on "The Nasal Accessory Sinuses" by Emil Mayer, M.D., Ad-

* Read in the Section on Stomatology of the American Medical A scociation, at the Fifty eighth Annual Session, held at Atlantic City. June, 1907 . junct Attending Laryngologist to Mount Sinai Hospital, Chief of Clinic, Ear and Throat Department of the Mount Sinai Hospital Dispensary, New York. Read before the Metropolitan Medical Society, New York City, March 2\%, 1906, and is to be found in the division of the article, "Etiology of Sinus Affection."

It is a regret that no published discussion of the article followed, as it would have been of interest to learn the impression such a condemmation of a useful, comfort-giving prosthetic treatment had on the hearers.

Is this statement worthy to be discussed before this section? No; so far as the intelligent understanding of sinus affections and the rôle diseased teeth take in producing it, are appreciated by those in attendance. If there were no other reasons, we might smile and let it pass. But what impression has it made on the minds of those wishing enlightenment on the etiology of sinus affections who are not familiar with the worth the practice of stomatology has won in benefiting human kind? This and the reflection it has on our prosthetic treatment are the most vital reasons for presenting a rebuttal to such presumption.

The covering of teeth with metal crowns a cause of sinus affection! How? What kind of metal, gold or platinum, as each is used? Porcelain does not appear to have such an effect, in the opinion of the writer of the paper, though many roots are more frequently crowned with porcelain than with metal by the ethicallyinclined practitioner, and often crowns of teeth with defective enamel are covered with porcelain. But it is a crown of metal we are to deal with, though it is not specified whether as a cause it is direct or indirect.

Presuming, as a working hypothesis, that a metal covering is a cause of sinus affection, how can it by logical reasoning be demonstrated? Perhaps the roots of a superior molar were found to extend into a sinus that was in an empyematous condition, a glance into the mouth revealing said molar covered with metal. Ellreka! It is the metal covering causing the tromble. One is reminded of a student who accompanied his preceptor on the visitation of patients and was impressen with the keen observation and logic of the experienced doctor when a patient was told, without any apparent information being given, that he should not again eat oysters during his indisposition. The student being somewhat perplexed as to how the knowledge was obtained, on leaving the sickroom asked how it was known that the bivalves had been indulged in, and received the reply: "I saw the shells under the bed." On a subsequent day the student was sent to see and report the condition of the sick one, and returned with the startling information that the patient had eaten a horse, as there was a saddle and bridle under the bed.

\section{ANATOMIC RELATTONSIII.}

In reviewing the relation of the teeth to the maxillary sinus we are reminded that the floor of the sinus is situated over the superior molar and premolar teeth and may descend between their roots; it is lined with a mucoperiosteum covered with ciliated epithelium, and the bone forming it is cancellous in character. The roots of the superior teeth are situated within the cancellous portion of the maxillary bone and often extend so far upward as to form the uneven outline on the floor of the antrum. The wall between the apices of the teeth and sinus is in some cases exceedingly thin, and in rare cascs is absent, leaving only the mucoperiosteum covering crer the end of the roots as they extend into the antrum. 
A tonth consists of a pulp, dentine enamel and pericenental membrane. The pulp is the formative organ of the dentine and, after that function is fulfilled, is the medium of furnishing nutriment to that tissue. It is situated within a chamber in the central portion of the tecth, and in shape somewhat resembles the tooth it is related to. It is formed of loose connective tissue and cells, blood ressels and nerres, the last two entering the organ at the apex of the tooth.

The dentine is a hard, transparent substance composed of an organic matrix impregnated with calcareous salts; through this matrix radiates tubuli from the central cavity containing a soft fibril, which take their origin from the cells of the pulp lying next to the dentine.

'The enamel is a hard substance investing the crown portion of the troth. It is the hardest tissue found in the animal body, is low in organic constituents, and may be said to be a coat of mail for the protection of the tooth. The cementum in the human tooth is an investment for the roots and resembles bone in histologic character, and it is covered with the pericemental membrane which unites the root with its alveolus.

\section{PATHOLOGIC CONSIDERATION OF THE TEETH.}

The pulp and the condition of the pulp ehamber is of importance in considering the treatment of the teeth, whether it be for the simple operation of filling for the arrest of caries, the placing of an artificial crown on a root, or covering the dentine with metal or porcelain as a substitute for the coat of mail.

If by a blow or the encroachment of caries of the dentine the vital force of the pulp is so reduced that it succumbs and gives up its life, fermentation and decomposition, with the concomitant phenomena that obtain after death in tissue of like endowment, follow.

The process is an analytic one, taking place through the agency of micro-organisms terminating in the production of poisonous ptomains, and if no interference is preseribed the peridental membrane becomes inflamed, pus is formed and a pathologic condition known as alveolar dental abscess is presented.

During the progressive stages more or less of the poisonous products are absorbed by the dentine and cancellated bony structure and perhaps the mucoperiosteum of the floor of the antrum become affected should the apices of the roots of the affected tooth extend close or in to the sinus.

\section{MALPRACTICE.}

If a tooth containing a devitalized pulp be filled or crowned without converting the poisonous mass within the pulp chamber into non-poisonous and harmless matter, the remoral of the same and the filling of the chamber to the apical foramen the diseased condition will not be abated but aggravated, and a condition established more severe and dangerous than the former. Such practice, however, is not dentistry, and he who resorts to such methods is unworthy of being called a dentist. The placing of the filling or crown is an act of ignorance or indifference to the necessity of a return to normality before substituting an artificial part, and is as wrong as to charge a syringe with water impregnated with cadaverin and putrescin and inject it into the tissues. The practice of covering teeth with metal govering during a condition that is possible to pass into a pathologic one of greater magnitude is as deserving of condemnation as the removal of the vermiform appendix without preparing the field of operation, and proceding with the operation with indifference to anti- septic and aseptio methorls, or the placing of an artificial limb on a gangrenous stump and expecting the limb to perform its function with comfort and without interference to the process of repair.

\section{OTHER STATEMEXTS FALSE IN TIIEIR APPLICATION TO} DENTISTRY.

Dentistry has often been brought in contact with statements from general practitioners of medicine that are reflections on the science and art that constitute it. The devitalizing of pulps with arsenic trioxid, the use of amalgam for filling cavities produced by caries, have been condemned without reasoning or obtaining data from those learned in pathology of the teeth and other tissues of the oral cavity and the therapeutic properties of drugs and material employed in treating discases which are within the province of dental practice.

We have heard of late that the substituting of lost tecth by a bridge is a menace to the health of the indiridual wearing such. With but a limited knowledge of oral prophylaxis one can observe that many bridges and crowns worn in the mouth should be relegated to the scrap pile and the patient be the better for it. It can also be observed that bridge work and crowns placed in the mouth after proper preparation of the tissue tiecy rest on. are helpful adjuncts in maintaining hygienic, oral condition, and instead of being a menace to the general health, are serving useful assistance in aiding digestion and promoting healtl. To thousands of intliriduals who would be obliged to relinquish social and professional duties "they are lengthening out the enjorable period of human existence."

\section{DISCRIMINATION.}

Let there be a discrimination between true surgery of the teeth and their associated parts that appreciates and comprehends the antiseptic and aseptic treatment that antedates and accompanies the art of repair and the commercial practice that passes by those fundamentals. We are specialists and our work approximates the work of other specialists, that of the laryngologist and rhinologist in no small degree. and all who would familiarize themselves with their own specialties should appreciate that of others and work in unison and diffuse knowledge that will be helpful. Insinuation and false statements but divert the sympathetic harmony, while unity of thought and study will divide the ethical from the commercial in all.

\section{DISC CSSION}

Dr. Fraxcis A. FaugitT, Philadelphia, referred to erroneous statements apparently coming from authentic sources and appearing in scientific journals, exploiting proprietary drugs and obscure preparations which appear quite profusely in the dental magazines, but which, of course, do occur and have occurred more frequently previously in medical journals. He mentioned, particularly, antikamnia, which is advertised in rep. utable journals, although it has been absolutely condemned by the Council on Pharmacy and Chemistry of the American Medical Association: Also Campho-phenique, a preparation which has been advertised as containing certain ingredients in certain proportions, but which has been found by analysis to have an entirely different composition. Tyree's Antiseptic Powder is adrertised extensively among dentists and has been given testimonials by dentists. This has been analyzed by the Council on Pharmacy and Chemistry and shown not to be as advertised, both as to the claims made as to its composition and the effects to be derived from its use. Dr. Faught stated that there are many reputable preparations about which little is known, and many combinations which dentists and physicians might make themselves if they were 
better versed in therapeuties and materia medica. Where they can use preparations of their own combining from pharmacopeial drugs, they should do so, in preference to purchasing any proprietary preparation, no matter how ethical, and especially those preparations which have been shown to be practically fakes.

The Couneil on Pharmacy and Chemistry, Dr. Faught contimued, examines remedies which have been advertised to the profession, and somewhat to the laity, and for which elaims have been made that they contain certain percentages of certain substances combined in certain ways, etc. The Couneil is made up of physicians and pharmacists. It is not a work for which the nembers are paid, but a labor of love, and their stamp of approval on a preparation should certainly give it at least preference in practice, as compared with something which they have shown by their examination of samples purchased in the open market, to be false; in other words, to contain substances which have not been advertised or to contain substances in proportions not as advertised. Dr. Faught said that in addition to the three preparations he mentioned there are others which have been shown to be nothing like the descriptions of the preparations put on the market to sell to the laity and the dentist. He urged dentists to give their patients the benefit of the doubt and prescribe ethical preparations or write prescriptions of preparations of their own combining, and not the preparations advertised by manufacturers who are manufacturing for profit solely.

Dr. V. A. LathaM, Chicago, expressed her belief in the mechinical side of the profession, but stated that it should be applied with an anatomic reason. Without considerable work on the condition of parts and teeth, it follows that it is exceedingly difficult to maintain a bridge satisfactorily on its posts. Again, the cleaning of a bridge is a very hard piece of work, in view of some of the positions in which bridges are placed. Few patients wearing bridges have mouths that are not much more disgusting than they otherwise would be, and Dr. Latham can not but feel that for people to wear so many mechanical devices is bad hygiene. Therefore, the greatest blessing is preventive dentistry.

Dr. James Truman, Philadelphia, said that he understood Dr. Luckie to quote some one as having stated that the crowning of the molar teeth of the upper jaw is likely to produce abscess in the antrum. Why should it not, he asked, produce it? If there is one pathological condition to which dentists, as a rule, pay no attention, it is the fact that they can not interfere with the proplasmic contents of the tubes, exposing the contents of those tubes to thermal irritation, without caus. ing the death of the pulp. This operation of erowning is done every day. If it extends to the removal of the enamel, and this is liable to occur, the result will be, necessarily, the destruction of the pulp which, through inflammation, may produce peridental inflammation, and peridental inflammation results in abscess, and thus the whole cycle of inflammation is presented, eventually resulting in abscess in the antrum. Dr. Truman was surprised that Dr. Luckie should take the position that the quotation is incorrect. The pathologic conditions that follow many of these operations are to-day among the most important matters that ought, in his judgment, to be con. sidered in any dental association. The average dental operator is working on cases every day in practice, without a particle of regard for the sequelæ that may result. He will place a band on the peridental membrane and force it down until he produces irritation. The pain that follows will gradnally subside. He will dismiss the patient, and in the course of a few months, or at most a year or two, the peridental membrane is destroyed, necrosis of the cemental tissue takes place and death of the tooth follows. The pathologic result is not an uncommon occurrence. It is liable to occur in any mouth treated for crowns or bridges.

The dictum that went from Chicago some years ago, of extension for prevention, Dr. Truman regards as another one of those fallacious ideas that dentists should consider seriously. The idea of cutting down an approximate surface of a tooth below the free gum margin, and expecting that this will subserve the interest of that tooth, is all wrong, he said. Dr.
Truman does not condemn all these so-called progressive changes in dentistry, neither does he condemn the crown or the bridge; but he wanted to impress on those who purform these operations that they must always remember the possible pathologic conditions that may follow work on the sensitive portions of the human organism, and that if this is not done, then dentistry will fail to the extent of the lack of judgment manifested.

Dr. M. I. Schambeng, New York City, believed, with Dr. Truman, that a just recrard must be had for the pathologir conditions that arise from the insertion of crowns under aclverse conditions; but to allude to a gold crown on a tooth as a cause of antral empyema, he considered misleading to the medical profession and the lay public, who would regard all crown and bridge work as a practice to be condemned. For that reason. Dr. Schamberg agreed with Dr. Luckie that it is well. from time to time, to hold in eheck investigators who jum; hastily at conclusions, and off-hand make the statement that antral empyema is the result of the insertion in the mouth of gold crowns. The same condition would arise with the insertion of too large a gold filling impinging on the gum or allowing a sick pulp to remain in the tooth.

DR. H. C. Registen, Philadelphia, asked whether the tonth referred to was a vital one or a devitalized one. He undorstood how a metal crown placed on a vital tooth can, through thermal and chemieal influences, cause it to be devitalizel, which would probably, as Dr. Truman explatined, terminate in abseess of the antrum.

Dr. George V. I. Brown, Milwaukee, Wis., emphasized the danger of hasty diagnosis with regard to empyema of the maxillary sinus, because, he said, it is an exceedingly difficult matter to decide this doubt of a known pathologic condition of the teeth in connection with the maxillary sinus. Of six patients he operated on, two had histories directly connecting the trouble with diseased molars. As a matter of fact, when those antrums were thoroughly opened up, it was verv evident that in each of those cases the tooth condition was merely coincident. The real trouble was disease coming from the nose. Dr. Brown emphasized that of the small percentage of crses of empyema in antra coming from some condition of the teeth, the dentists are responsible for the empyema.

Dr. F. I. Fossume, New York City, presented the case of a man, about 60 years of age, who complained of a pain on the left side of his face, especially marked at night. His family physician, who had first been consulted, sent him to a rhinologist, who treated the posterior part of his nares. There was considerable discharge from the nose. The last molar too:h being particularly sensitive to concussion, however, the patient consulted Dr. Fossume, who tested the molar and found it normal. He then had a radiograph made; this demonstrated a small tooth root located immediately in front of the sensitive tooth, which had remained in situ for fifteen years. The root piece was removed, and as it encroached on the antrum, this was opened in its extraction, a free pus flow ensuing from the maxillary antrum. The antrum was treated in the usual way, and, the case responding to treatment, healed in three weeks.

Dr. S. B. Lucrie, Chester, Pa., stated that the point he wished to make was not the placing of the crown on the tooth, but the unscientific manner in which it was done, the lack of discrimination in putting it there, that caused the disease. It is not placing the bands on the teeth, but driving them against the peridental membrane that produces inflammation, a lack of care in preparing for the operation.

With reference to the use of proprietary preparations, Dr. Luckie suggested the appointment by the section of a Committee on Pharmacology. Dentists could then find out all about the cements and whether they contain anything that would be hurtful, and what tooth powders and preparations that are used in pulp canals are composed of without taking the word of the maker. Tyree's Antiseptic Powder, he said. is not what it has been advertised to be; and the same criticism may be made of campho-phenique and other preparations. There should be some way of selecting those proprietary articles that are scientific preparations and which can be used with safety. 